\title{
O COMPORTAMENTO DE DEFERÊNCIA: DO CORTESÃO À PERSONALIDADE DEMOCRÁTICA*
}

\section{Deference: from the behaviour of courtiers to the}

democratic personality

Claudine Haroche**

\section{RESUMO}

O presente artigo pretende colocar em evidência o papel da deferência como constitutiva do "eu", sendo considerada sua origem na sociedade da corte. Num segundo momento, o artigo procura discutir como diversos autores apreenderam a deferência como um código de comportamento entre indivíduos que se considerem iguais, condição imprescindível para o convívio democrático.

Palavras-chave: deferência, personalidade democrática.

\section{ABSTRACT}

This article aims to put in evidence the role of Deference as a behaviour constitutive of the "I", its origin being considered within the court society. It also tries to show how several authors understand Deference as a code of behaviour amongst individuals who consider themselves as equals - an indispensable conditon for democratic conviviality.

Key-wors: deference, democratic personality.

* Tradução de Jacy Alves de Seixas. Publicado originalmente em "La Déférence", Communications, Paris, Seuil, n. 69, p. 5-26, 2000

** Université de la Sourbonne Nouvelle - Paris I - França. 
Em 1959, em nota-de-rodapé de obra consagrada aos ritos de interação, Erving Goffman agradece a Edward Shils por ter-lhe sugerido trabalhar sobre o comportamento de deferência. ${ }^{1}$ Goffman vê na deferência um conceito que designa ao mesmo tempo um tipo de comportamento, um sistema de regras de conduta, um conceito capaz de abranger as interações subentendidas tanto nas relações sociais mais cotidianas e insignificantes, "as mímicas mais fugazes", como nos mecanismos institucionais mais estruturados e visíveis nas sociedades.

Poucas linhas são suficientes para Goffman esboçar o modo de funcionamento e a função da deferência em uma sociedade:

Pela palavra deferência, eu designo um componente simbólico da atividade humana cuja função é exprimir nas regras destinadas a um beneficiário a apreciação a ele dirigida, ou a qualquer coisa da qual ele é o símbolo, a extensão ou o agente. ${ }^{2}$

Goffman busca estudar as maneiras pelas quais, em nossa sociedade, a pessoa se vê reconhecida de forma eloqüente ainda que imprecisa, uma "espécie de sacralidade". Esta sacralidade exprime-se por comportamentos, gestos, posturas e posições submetidas a regras. Recorrendo a termos referentes àquilo que chama de "antropologia comum", Goffman seleciona dois conceitos que

1 Ver: GOFFMAN, Erving. Les Rites d'interaction. Paris: Minuit, 1974. p. 51.

2 Ibid., p. 50-51. 
julga determinantes ao reconhecimento e ao funcionamento da sacralidade da pessoa: a deferência e a postura.

Debruça-se, assim, sobre as regras de conduta que configuram a deferência, e inspiram-na. Observa que "em todas as sociedades, as regras de conduta tendem a se organizar em códigos que garantem as conveniências e a eqüidade", precisando que, nas nossas, as regras de conduta que chama de cerimoniais distinguem-se daquelas que designa como substanciais: as primeiras concernem à etiqueta; as segundas, à moral e à lei. ${ }^{3}$

Destacando a presença desses dois tipos de regras em todas as sociedades, Goffman enfatiza, no entanto, que as partes do componente cerimonial e do componente substancial não são necessariamente idênticas: certas atividades comportam uma parte substancial enquanto que sua parte cerimonial parece negligenciável; mas, prossegue, "toda atividade cuja importância é primeiramente substancial comporta igualmente uma certa significação cerimonial." ${ }^{4}$

Goffman define a regra "cerimonial" como

\begin{abstract}
...uma regra que guia a conduta em relação às atividades consideradas pouco importantes, ou totalmente sem importância nelas mesmos, mas que valem antes de mais nada - oficialmente pelo menos - como meios de comunicação convencionais graças aos quais o indivíduo significa seu personagem ou porta uma apreciação sobre os outros. ${ }^{5}$
\end{abstract}

Ao distinguir as regras cerimoniais das regras substanciais pela importância de que se revestem para os indivíduos, percebe entretanto entre elas uma continuidade, que reside na existência de uma parte cerimonial nas interações cotidianas, tanto quanto nas situações solenes: “...esforçando-me para sublinhar o que aproxima os apertos de mão das coroações, serei levado a negligenciar aquilo que os separa, a um ponto tal que muitos antropólogos julgarão excessivo..."

3 GOFFMAN, op cit., p. 49

4 Ibid., p. 50. Daniela Romagnoli vê uma diferença análoga nos tratados de civilidade, que fixam a existência de um vínculo profundo entre a ética e a etiqueta. Cf.: ROMAGNOLI, D. La courtoisie dans la ville: un modèle complexe. In: ROMAGNOLI, D. (Ed.) La Ville et la cour. Des bonnes et des mauvaises manières. Paris: Fayard, 1995. Prefácio de Jacques Le Goff.

5 GOFFMAN, op. cit., p. 48-49. 
Reconhece, então, se "afastar do uso comum do termo 'cerimônia', carregado de conotações solenes". ${ }^{6}$

A deferência sobre a qual Goffman busca apoiar-se - a deferência cerimonial - é aquela que se estabelece entre dois indivíduos no curso de breves interações ou, pelo menos, limitadas no tempo. Cita como exemplos as saudações, cumprimentos e desculpas, acrescentando que "todo ato de deferência implica da parte de seu autor uma certa consideração que inclui, freqüentemente, uma apreciação global do beneficiário". ${ }^{7}$ Observa, igualmente, que se esse tipo de interação parece relativamente clara, o sentimento que a acompanha o é muito menos: sendo "banal", é "no entanto difícil de ser definido precisamente". A importância desse tipo de sentimento revela-se quando se considera que Goffman ressalta, em muitas passagens, o papel da deferência obtida junto aos outros na constituição do eu. ${ }^{8}$

Além disso, a expressão de deferência não se limita necessariamente ao momento preciso da cerimônia e nem se limita, sempre, à deferência formal, tangível. Ou seja, a deferência pode ser difusa, atenuada e sem importância. Pode, ao contrário, apresentar-se difusa mas ter uma importância decisiva. $\mathrm{O}$ que é precisamente difícil de ser avaliada é esta deferência impalpável e, no entanto, essencial.

Discernindo na deferência um mecanismo inerente às sociedades, relativo a questões que dizem respeito às cerimônias, ritos e interações, Goffman adota uma abordagem antropológica e sociológica análoga, em muitos aspectos, a de Spencer para os cerimoniais, e as de Tönnies e Simmel para o costume. ${ }^{9}$

A antropologia britânica - com os trabalhos de Spencer, a partir de 1879 - e a sociologia alemã - com os de Tönnies, em 1909, e os de Simmel, em 1908 - formularam as categorias-chave da sociologia, seus conceitos

6 GOFFMAN, op. cit., p. 49.

7 Ibid., p. 52.

8 As análises de Goffman são próximas das desenvolvidas em certos trabalhos jurídicos, como os de teoria moral e jurídica incidindo sobre a dignidade e outras questões relativas ao reconhecimento. É o caso, particularmente, dos escritos de Robert Post, que, retomando recentemente as questões tratadas por Goffman, lembra que "a integridade da pessoa individual depende em parte da observância das regras de deferência" (POST, Robert. The Social Foundation of Privacy: Community in Common Law Tort. California Law Review, v. 77, n. 3, 1989; apud HAROCHE, Claudine. O direito à consideração: notas de antropologia política e história. Estudos de História, Franca, 2004).

9 SPENCER, H. Ceremonial Institutions. London: Williams and Norgate, 1879. Part IV, "Principles of Sociology"; TÖNNIES, F. Die Sittre. Glencoe: The Free Press of Glencoe, 1961. Trad. Ingl. On Custom; SIMMEL, Georg. Custom, Law, Morality. In: WOLFF, Kurt H. (Ed.). The Sociology of Georg Simmel. New York: The Free Press, 1950. (Soziologie, 1908). 
fundamentais, e refundaram as bases da antropologia. ${ }^{10}$ Esses trabalhos analisaram profundamente, valendo-se de um enfoque essencialmente sociológico e antropológico (com exemplos tirados ora da história, ora da antropologia e do jurídico), questões como as instituições cerimoniais, as origens dos costumes, as relações entre costume e moral, entre as formas e os conteúdos da sociabilidade. Permitiram a inscrição da deferência em um quadro teórico geral, ressaltando os elementos que a fundam, subentendem, envolvem e inspiram: a questão mais ampla do costume - referimo-nos à deferência devida à idade, aos mais velhos, à tradição.

Presentes nas análises de Goffman sobre a deferência, os textos de Spencer, Tönnies e Simmel nos convidam a uma abordagem genérica das formas, conteúdos, origens e modos de exercício da deferência. Shils, por sua vez, irá sublinhar a necessidade de se aproximar a deferência do prestígio, da honra e do respeito, do renome, da glória e da dignidade.

O conjunto dessas análises nos leva a reconsiderar a questão do valor social de um indivíduo, tanto a seus próprios olhos como aos olhos dos outros, a questão da auto-estima; a considerar ainda uma vez a relevância da problemática dos sentimentos morais. Sob esta ótica, tentar compreender em que um tipo de sociedade, a sociedade desigualitária do Antigo Regime, difere de uma sociedade democrática no modo de obtenção e atribuição da deferência, e também no tipo de comportamento e de personalidade que implica: as instituições democráticas querem dar uma alta idéia de si, de seu valor pessoal, em função da qualidade do ser humano e de seu mérito pessoal; as sociedades aristocráticas, subordinando o valor de cada um à sua condição, à hierarquia que ocupa na sociedade..$^{11}$

10 Ver, também, os trabalhos de WEBER, M. Économie et Société. Paris: Plon, 1971. t. I, "Les catégories de la sociologie, les concepts fondamentaux de la sociologie" (em particular a passagem consagrada ao costume, p. 61-63).

11 TOCQUEVILLE, Alexis de. De la démocratie en Amérique. 1. ed. histórico-crítica revista e ampliada por Eduardo Nolla. Paris: Vrin, 1990. 


\section{Nas origens da deferência: as cerimônias e os costumes}

Spencer localiza as origens das formas da deferência nas instituições cerimoniais mais antigas das sociedades humanas; elas precederam todas as formas de organização religiosa, jurídica e política. Sublinha, sobretudo, que a existência de formas implicando a subordinação constitui "o fato político mais antigo narrado na história européia":

Nas épocas em que se colocava a questão de saber quem deveria dominar nos pequenos e nos grandes territórios, eram raras as formas de regulação que as formas de governo civil iriam mais tarde instaurar. ${ }^{12}$

Por outro lado, eram constantes a submissão e a subordinação exprimindo a humildade e a deferência, traduzindo-se em gestos, em posturas, na inclinação e, muitas vezes, na prosternação do corpo.

Spencer ressalta a importância dos juramentos de fidelidade aos superiores e das recorrentes manifestações de lealdade, nas quais "o vassalo que se ajoelhava, descoberto e sem espada diante de seu suserano, engajava-se a se submeter e entrava, então, de posse de suas terras." ${ }^{13}$ Enfatiza que, nessas cerimônias, a deferência se traduz de diversas maneiras por meio de formas que possuem uma intensidade mais ou menos forte, como a prosternação no interior do espaço religioso, em seguida, face ao senhor ou ao monarca. Fala da "genuflexão em presença dos ídolos, dos chefes e dos companheiros" e que "descobrir a cabeça é um sinal de reverência, de lealdade e respeito". ${ }^{14}$

A importância das cerimônias tende, no entanto, a desaparecer lentamente, suas funções sendo progressivamente substituídas por regulamentações políticas e religiosas. Estas últimas vão, no início, "insistir sobre a conduta exprimindo a submissão, a obediência aos governantes homens aos deuses -", em seguida, com a promulgação de regras morais, vão desenvolver-se e afirmar-se na perspectiva de constrangimentos interiorizados, igualmente compartilhados, distribuídos, repartidos. Essas regulamentações,

12 SPENCER, op.cit, cap. I, "Ceremonial in General", p. 6-7. Tradução da autora.

13 Ibid., p. 7. Ver, também, LE GOFF, Jacques. Le rituel symbolique de la vassalité. In: LE GOFF, Jacques. Pour un autre Moyen Âge. Paris: Gallimard, 1991.

14 SPENCER, op. cit., p. 12. 
que se acompanham de uma atenuação das posturas, vão ser exercidas sobre as condutas entre os indivíduos. Os preceitos éticos, servindo de guia aos comportamentos, contribuirão para reduzir cada vez mais a esfera das instituições cerimoniais. ${ }^{15}$

A análise de Spencer contribui para esclarecer o declínio das formas corporais de subordinação explícita, aspecto que Firth ressaltará, assim como para esclarecer o processo ressaltado por Goffmann, ou seja, a existência de uma continuidade entre cerimônias e interações cotidianas, "apertos de mão e coroações". ${ }^{16}$

Pode-se ir além da constatação de que a deferência é apenas uma dimensão constitutiva do cerimonial? Se ela nasce das cerimônias, exprime também uma necessidade elementar, uma disposição fundamental da pessoa, a tal ponto que Goffman pôde pensar a deferência como um atributo fundamental do ser humano.

Os trabalhos de Simmel e Tönnies sobre o costume contribuem, igualmente, para o entendimento do modo de funcionamento da deferência. Simmel sublinha, em abordagem análoga a de Spencer - que enfatizou as cerimônias como anteriores ao religioso e ao direito -, a existência de um estágio de indiferenciação, no qual os costumes constituíam "a única forma de regulamentação". Esboça, então, um quadro teórico geral de funcionamento das interações sociais, assim como métodos de observação para as interações individuais mais intangíveis. É no interior desse quadro que, mais tarde, se inscreverá Goffman quando, distinguindo regras cerimoniais e substanciais, coloca que as segundas referem-se à moral e à lei.

Tudo aquilo que se manifesta nos e entre os indivíduos (...) sob forma de tendências, interesses, fins, inclinações, conformidade e mobilidade psíquica, eu designo como o conteúdo, de alguma forma a matéria da socialização. A socialização é, portanto, a forma que se realiza seguindo inumeráveis e diferentes maneiras, graças as quais os indivíduos, em virtude de interesses - sensíveis, momentâneos ou duráveis, conscientes ou inconscientes (...) -, se soldam. Esta vida tão vibrante que liga os seres uns aos outros revela, para além das formas de associação que aspiram o título de vastos

15 SPENCER, op. cit., p. 12.

16 Ver, a propósito do declínio das formas de subordinação, THOMAS, K. Introduction. In: BREMMER, J.; ROODENBURG, H. (Eds.). A Cultural History of Gesture (from Antiquity to Present Day). New York: Polity Press, 1991. 
organismos, um número enorme de outras formas que permanecem de alguma maneira em estado de fluidez e movimento, mas sobre as quais se fundam as relações dos indivíduos e se formam o estado social. Pessoas que se observam, se invejam, se escrevem, jantam juntas, vestem-se e enfeitam-se umas para as outras, atraem-se ou repudiam-se independentemente de qualquer interesse palpável. ${ }^{17}$

Apoiando-se sobre a tradição, Tönnies coloca que o costume é imemorável. As práticas ancestrais são consideradas, sublinha esse autor, o fundamento essencial dos deveres aos quais os homens se apegam. Pode se tratar de uma reverência, como aquela que as crianças testemunham a seus pais:

Tal reverência é geralmente considerada como um dever. Esta reverência, intrinsecamente, não é fundada sobre o costume mas sobre a natureza, sobre a "lei natural", isto é, sobre uma compreensão tácita daquilo que deve ser. ${ }^{18}$

Tönnies recorre, como exemplo, ao termo "reverência" em alemão:

A palavra "reverência" (Ehrfurcht) é composta em alemão de "honra" (Ehre) e de "medo" (Furcht). É natural que o fraco "honre" o forte e que a criança "honre" o adulto. "Honrar" significa admirar, considerar como grande e poderoso. Ao mesmo tempo, "honrar alguém" significa considerá-lo como bom, isto é, de alguma maneira generoso e gentil em relação aos outros. (...) É também natural que o fraco tema o forte e a criança seus pais. A reverência se fundamenta no fato que aquele que é temido não é rejeitado nem detestado como um inimigo, mas estimado e honrado como um amigo, um apoio e um reconforto, como um senhor e mestre. Ora, a reverência é nela mesma este terror vago que (...) emana de uma atitude venerável e traduz-se de uma forma misteriosa e solene. ${ }^{19}$

17 SIMMEL, Georg. Sociologie et épistémologie. Paris: PUF, 1981. p. 122 e 224, "La sociabilité: exemple de sociologie pure et formale" e "Essai sur la sociologie des sens".

18 TÖNNIES, op. cit., p. 44-45. Tradução da autora.

19 Ibid., p. 45. 
A deferência aparece, portanto, como um aspecto das cerimônias, uma dimensão dos costumes. Para além dos usos, regras e costumes, gostaríamos de aprofundar o conteúdo da deferência, a necessidade que ela revela, o sentimento que suscita, os comportamentos que a exprimem por meio de excessos e ausências. ${ }^{20}$

\section{A deferência: questão de forma ou de fundo?}

Ao abordar questões fundamentais como as da dignidade, da honra, do julgamento social e da etiqueta, dos ritos de apresentação, o texto de Goffmann traz um grande número de observações e intuições marcantes. Sua leitura coloca uma questão: o que entender por deferência? Trata-se de uma conduta relativamente codificada que se traduziria por gestos ao longo de ações delimitadas no tempo? Trata-se de um comportamento que, acompanhando interações individuais, respondendo a necessidades e sentimentos profundos de estima, de consideração, possuiria necessariamente um caráter difuso? A deferência dirigida a uma pessoa varia em função das sociedades, das condições, das posições, do valor social de um indivíduo, ou depende das qualidades específicas do ser humano?

Parece-nos interessante prosseguir o trabalho de Goffman desenvolvendo certos elementos de sua análise à luz dos escritos de La Bruyère e Tocqueville. ${ }^{21}$ Os de La Bruyère, sobre a sociedade de corte do século XVII, constituem uma fonte de incomparável riqueza para a análise dos comportamentos e dos caráteres nas lutas de poder. Contribuem a elucidar

20 A maior parte dos sentimentos morais, bens ou atributos da pessoa são difíceis de definir de maneira positiva e tornam-se sensíveis e perceptíveis apenas quando estão ausentes. Assim é com a dignidade: percebemos sua necessidade por meio de sua falta e dos atentados de que somos objeto. Ver, a propósito, "Incertezas e ambigüidades do direito à dignidade", nessa coletânea.

21 LA BRUYĖRE, J. de. Les Caractères ou les moeurs de ce siècle. Paris: Gallimard, 1951. Oeuvres Complètes. (Bibliothèque de la Pléiade); TOCQUEVILLE, op. cit. 
certos aspectos subjacentes aos mecanismos mais profundos e, muitas vezes, imperceptíveis das sociedades. ${ }^{22}$

Para além da "sociologia das circunstâncias" pretendida por Goffman, desenha-se nos escritos de La Bruyère uma antropologia social que exprime um ponto de vista moral e ético sobre a qualidade das condutas e dos caráteres, um julgamento de valor sobre o fundamento e o conteúdo dos comportamentos, e não apenas sobre as formas ou as regras, uma sociologia das condições que revela a existência de mecanismos fundamentais da sociedade. ${ }^{23}$

À maneira de Elias - que desenvolveu, partindo das Mémoires de Saint-Simon, uma análise sociológica dos mecanismos da sociedade de corte -, apoiamo-nos aqui sobre a observação de La Bruyère sobre os caráteres e costumes do século XVII, e sobre a análise comparada que Tocqueville consagrou, com base na observação das sociedades do Antigo Regime, às maneiras e temperamentos para assinalar certas similaridades com os das sociedades democráticas. ${ }^{24}$

As demonstrações de deferência podem exprimir-se e reforçar-se por meio de certos comportamentos: um gesto, uma contenção, uma postura, "uma pose que manifeste insolência ou obsequiosidade", e também pela posição no espaço, "o fato de passar em primeiro lugar ou de sentar-se mais à direita do que à esquerda de alguém", observa Goffman. Mas, ao observar que "pode acontecer que o suposto beneficiário não receba as marcas de deferência que esperava, ou perceba que as recebe com uma evidente má vontade", ou ainda que "às vezes um indivíduo estime que a deferência que lhe testemunham não the seja apropriada, seja porque ela o situe muito acima ou o rebaixe em excesso", Goffman nos convida a retomar La Bruyère, que discerne nos comportamentos de deferência tanto os excessos como as carências: a bajulação,

22 Atendo-se ao mérito, Roland Barthes sublinhava que "pelo menos a metade das classes de objetos referidas por La Bruyère não tem mais do que uma existência vetusta; ninguém hoje faria um capítulo sobre as mulheres, o mérito ou a conversação: ainda que continuemos a nos casar, a 'vencer na vida' ou a falar, estes comportamentos passaram a um outro nível de percepção". E acrescentava: "se chegamos a pensar no 'caráter" de alguém, é para experimentar a universalidade insignificante (o desejo de promoção social, por exemplo) ou a complexidade intraduzivel (quem ousaríamos hoje chamar de enfatuado?)", concluindo: "em suma, o que mudou do mundo de La Bruyère ao nosso é aquilo que é digno de ser notado: nós não percebemos mais o mundo como La Bruyère" (cf. BARTHES, Roland. La Bruyère. Essais critiques. Paris: Ed. du Seuil, 1964).

23 Trabalhos de teoria moral e política têm se preocupado com os conteúdos de comportamentos em matéria de dignidade, de respeito ou de reconhecimento. Ver WALZER, M. Spheres of Justice. New York: Basic Books, 1983; HONNETH, A. The Struggle for Recognition. Cambridge, Massachusetts: MIT Press, 1996.

24 ELIAS, N. La Société de cour. Paris: Calmann-Lévy, 1974. Particularmente o capítulo "L'étiquette et la logique du prestige". 
a obsequiosidade, ou, ao inverso, a auto-suficiência, a condescendência, o desprezo. ${ }^{25}$

A deferência que extrapola o âmbito das cerimônias depende de regras morais, ou seja, de regras que guiam as condutas em assuntos considerados importantes em si: ela diz respeito ao mesmo tempo à auto-estima e à estima demonstrada ou experimentada em relação aos outros. Essas regras e comportamentos morais refletem certas necessidades essenciais dos indivíduos, determinando em profundidade a qualidade das relações tecidas entre eles.

La Bruyère, no livro Caracteres, dedicou-se precisamente à observação de tais comportamentos, referindo-se a regras gerais que remetem à idéia de um valor intrínseco aos comportamentos e às qualidades morais, independentemente das condições e do lugar ocupado pelas pessoas - ou a seu desmascaramento, à "corrupção dos sentimentos morais" que desvelam o excesso ou a carência no que se refere à deferência. ${ }^{26}$

\section{O amor pelos grandes, o ódio pelo igual}

Interessando-se por questões como o mérito pessoal, a sociedade, a corte, os "grandes", os julgamentos de valor, La Bruyère sublinha a falta de atenção para com o outro, a falta de consideração, a baixeza que pode chegar ao aviltamento, em um palavra, a ausência de (regras) moral(ais) nos comportamentos.

Detalha, nesse sentido, o caráter de Mopse, de Celse, de Pamphile e Drance. Todos eles cortesãos, dos quais observa atentamente as maquinações e intrigas: num momento, a bajulação ou a obsequiosidade; noutro, a insolência e a arrogância ou, ainda, a indiferença, a grosseria, a altivez. Confidentes, mediadores, intermediários, intrigantes, todos eles praticam o excesso ou, ao contrário, a carência de deferência: dando a aparência de negligenciar, ignorar

25 GOFFMAN, op. cit., p. 50 e 54.

26 Adam Smith referia-se à origem da corrupção dos sentimentos morais nos seguintes termos: "esta disposição a admirar e quase venerar os ricos e os poderosos, assim como a desprezar ou negligenciar as pessoas pobres e de condição humilde, ainda que necessária para estabelecer e manter a distinção entre as hierarquias e a ordem na sociedade é ao mesmo tempo a maior causa e a mais universal da corrupção de nossos sentimentos morais. Os moralistas de todas as épocas lamentaram que a riqueza e a grandeza sejam freqüentemente olhadas com o respeito e a admiração devidos unicamente à sabedoria e à virtude..." (SMITH, Adam. Théorie des sentiments moraux. Paris: PUF, 1999. p. 103). 
ou desprezar a ordem da deferência, eles insinuam-se, dela se utilizam para tentar manipulá-la com vantagens.

O cortesão é alguém que se agita, circula, desloca-se, esquiva-se; personalidade mutável, inconstante, inatingível, e que dá a impressão de ser mais instável do que realmente é: seu natural é não ter personalidade. Ele fala ou se cala, mas não diz e não deixa escapar nada de realmente importante. Ele vigia, espia para, enfim, lançar-se e colocar-se no bom lugar.

Ele se comporta sem contenção, sem reservas, sem tato. Sua força está naquilo que não sente, em nada sentir. Assim, não sente que importuna, atrapalha e incomoda. Ele não se sente bem ou mal: não conhece limites, não se coloca a questão daquilo que experimenta, ou daquilo que os outros experimentam em relação a ele. Não percebe a diferença entre os lugares, os espaços, as situações, as condições e as pessoas: ele é indiferente, cheio de si, satisfeito consigo, auto-suficiente. Raramente provoca a indiferença. Ele é mais ou menos suportado e tolerado, algumas vezes temido: ele aparenta não se importar com isso.

Sem olhar, sem palavra, sem sentimentos, sem atenção: Mopse pode, assim, visitar pessoas que não conhece. Para atingir seus fins, a via seguida é sempre a mesma: vigiar-se, policiar-se, ser falso, alternar a carência e o excesso.

Ele roga a pessoas que não conhece para levá-lo na casa de outras, onde não é conhecido.

Ele insinua-se no círculo das pessoas respeitáveis, que não sabem como ele é, e lá, sem esperar ser interpelado, sem sentir que interrompe, ele fala sem parar e ridiculamente. ${ }^{27}$

Nada o atinge, o toca ou fere; nada o demove em suas investidas. Sem profundidade, ele não tem pudor, dignidade, honra ou vergonha. Se ignora a ordem das deferências é por conhecê-la perfeitamente; ele se utiliza dela, manipula-a em proveito próprio, para poder insinuar-se, introduzir-se e dela apropriar-se.

Celse, igualmente, conhece todas as pequenas práticas que permitem introduzir-se em um círculo: “...os grandes o suportam, ele não é sábio mas tem relações com os sábios; possui poucos méritos, mas conhece pessoas que os tem em quantidade. ${ }^{28}$

27 LA BRUYÈRE, op. cit., p. 102.

28 Ibid., p. 103. 


\section{Mas, o que faz precisamente? Como procede?}

"...ele não faz nada, diz ou escuta aquilo que os outros fazem". ${ }^{29}$ Abusado e grosseiro, seu comportamento permite desvelar as rivalidades entre os cortesãos. Drance quer ostentar a proximidade, preencher assim a distância que o separa dos grandes - literalmente -, intervir nas posturas e reservas e, dessa forma, ultrapassar pela proximidade espacial, simbólica e psicológica seus rivais.

Drance é servil, dominador e perverso, "quer passar como governando seu senhor". Apresenta-se, então, com poses estudadas, mas é preciso que se interponha e interrompa os outros, chega ao ponto de "falar sem cessar a um grande [que ele serve], em lugares e na hora menos convenientes, falar-lhe ao pé do ouvido ou em termos misteriosos, rir às gargalhadas em sua presença, cortarlhe a palavra". É preciso que se posicione, "que se coloque entre ele [o senhor] e aqueles que lhe falam", e para isso é necessário que seja persistente: interporse com constância e, com teimosia e obstinação, dissuadir, desencorajar, afastar, desprezar, "desdenhar aqueles que vem fazer a corte [ao senhor] ou esperar com impaciência que se retirem, colocando-se próximo a ele e ostentando uma postura descuidada, tocá-lo e dar a impressão de ser familiar, tomar liberdades." ${ }^{30}$

A finalidade de todos esses movimentos e deslocamentos, de toda esta agitação: conquistar, manipular, dominar. Atingir a posição ambicionada, nela instalar-se e nela manter-se. Para isso, é preciso que manifeste excesso ou falta de atenção, de sensibilidade em relação às pessoas, às situações ou circunstâncias: ele ignora a polidez e as precedências.

Até que ponto pode ir a grosseria? Troïle pode "enrugar a testa", "desviar o olhar":

\footnotetext{
...quando abordado, ele não se levanta; se sentam perto dele, ele se afasta; se falam com ele, não responde; se persistem a lhe falar, muda de aposento; se lhe seguem, sobe as escadas; ele subiria andar por andar, preferiria jogar-se pela janela a reunir-se a alguém que tem um rosto ou um tom de voz que desaprova. ${ }^{31}$
}

29 LA BRUYĖRE, op. cit., p. 103.

30 Ibid., p. 144-145.

31 Ibid., p. 154 
Fascinado pelos grandes, Pamphile quer ser um deles. Ele existe apenas nas proximidades e sob o olhar de um grande. Pensa unicamente nas prerrogativas e dignidades. É obcecado pela idéia de grandeza - a sua -, de ser visto e reconhecido: que vergonha para ele ser visto com um homem simples, um pobre, um homem obscuro, sem relações!

\begin{abstract}
...se às vezes sorri a um homem do último escalão, a um homem de espírito, fá-lo num tempo tão curto que nunca é pego em tal ato: o rubor lhe subiria à face se fosse, numa infelicidade, surpreendido em ínfima familiaridade com alguém que não fosse rico ou poderoso, nem amigo de ministro, seu aliado ou empregado. ${ }^{32}$
\end{abstract}

Fugir do pequeno, esquivar-se de sua presença valendo-se de todos os meios; não hesitando mesmo a demonstrar voracidade. Assim, Pamphile é

\begin{abstract}
...severo e inexorável com aquele que ainda não fez fortuna. Ele vos percebe um dia em uma galeria e vos evita; no dia seguinte, se vos encontrar em um lugar menos público, ou mesmo público, na companhia de um grande, ele toma coragem, dirige-se a vós e diz: Ontem, parecia que não nos vistes. Ora ele vos abandona bruscamente para reunir-se a um senhor ou a primeiro secretário; ora, se vos encontrar em conversação, ele vos interrompe e os leva para longe. Vós o abordeis uma outra ocasião, ele não se deterá. Ele não se preocupa com os preceitos, menos ainda com os princípios. ${ }^{33}$
\end{abstract}

La Bruyère observa atentamente o homem de sucesso, aquele que conseguiu fazer carreira. É por meio de seu rosto, de sua postura que podemos perceber sua baixeza, sua falta de dignidade e compreender a falsa deferência: percebemos o obsequioso e adulador sob a roupagem do ambicioso, o arrivista querendo ter sucesso na corte. "Ele não chama mais cada coisa por seu nome; para ele todos são escroques, hipócritas, tolos e impertinentes.”

Ele submete suas opiniões e posturas a uma contínua vigilância, tem como práticas o eufemismo, o subentendido e as alusões, protege-se com o não-dito, instala-se na hipocrisia e duplicidade, na falsidade e mentira. É

32 LA BRUYĖRE, op. cit., p. 264-265.

33 Ibid., p. 265. 
desconfiado e teme dizer as coisas claramente; teme que assim procedendo sua ascensão possa ser entravada ou, pior, paralisada.

Aquele para quem evita dizer o que pensa, é o mesmo que se viesse
a sabê-lo o impediria de caminhar; pensando mal de todo mundo,
ele não fala mal de ninguém; querendo bem apenas a si mesmo,
pretende dissuadir que quer o bem de todos, a fim de que todos lhe
queiram bem, ou pelo menos ninguém lhe seja contrário.

Quais os efeitos de tal conduta sobre o seu comportamento? Ele é determinado, lacônico, sem brilho, "é circunspecto em sua conduta e em seus discursos"; é constrangido à prudência, à frieza, à indiferença e a fazer ouvidos moucos. Ostenta "um sorriso forçado, atenções disfarçadas, uma conversação interrompida e distrações freqüentes"; mostra-se covarde até o momento em que naturalmente se torna um covarde, de forma permanente e sem despender maiores esforços; assim, posiciona-se face "às observações feitas sobre a corte e sobre o cortesão; e porque as ouviu ele se coloca como cúmplice e responsável por elas". ${ }^{34}$ Mas sabe, também, na aparência, sair dessa frieza e exprimir um entusiasmo fingido, um calor glacial: não hesita, assim, a seduzir valendo-se da bajulação.

O amor pelos grandes é o que move o cortesão, aquilo que o ilumina. Sentimento que se alimenta da rejeição pelo pequeno, um amor pelo grande que se desdobra em ódio pelo igual. O cortesão é um homem de comportamento deslocado: recusando o lugar que é seu, quer a todo preço ocupar outro lugar, próximo de um grande; não que pretenda se opor a este último, lutar contra ele: quer se aproximar para se engrandecer (mesmo que para isto tenha que se rebaixar), anular as distâncias, quer "instaurar a proximidade" para dominar.

É legítimo pensar que o amor pelo grande, que o obseca, concretiza a auto-estima do cortesão; e que esta auto-estima, para ele, eqüivaleria ao amor pelo grande em si mesmo? Esse aspecto viria esclarecer o caráter de Lucile, que "prefere passar sua vida a se fazer suportar pelos grandes, do que se ver reduzida a viver familiarmente com seus iguais." ${ }^{35} \mathrm{Em}$ suma, um indivíduo que se sente rebaixado procuraria o grande para conseguir amar a si ou, pelo menos, suportar-se. 
Trata-se aqui de um desvio da auto-estima? O cortesão aparecendo, assim, como um homem inconsistente, sem qualidades particulares, oco, vazio, experimentando para existir, tanto aos seus olhos como ao olhar dos outros, a necessidade de se engrandecer apropriando-se de um grande.

O que fazer, então, interroga-se La Bruyère, "contra uma doença da alma tão impenitente e contagiosa"? Esquivar-se da dependência em relação aos poderosos: aspirar, procurar - ou, ao menos, suportar - a igualdade e, então, poder amar o igual, o semelhante. Ou ainda, aceitar ser aquilo que se é, não procurar ou se obstinar a ser mais, a possuir mais. "Contentemo-nos com pouco, e com menos ainda se possível for; saibamos eventualmente perder: a receita é infalível." ${ }^{36}$

Deparamo-nos, assim, com uma máxima profunda, que incita ao respeito a si, condição para o respeito ao outro, que evita "ser empurrado por uma porta pela multidão inumerável de clientes ou de cortesãos que deságua na casa de um ministro várias vezes ao dia; postar-se em sua sala de audiência; pedir-lhe uma coisa justa tremendo ou balbuciando, suportar sua gravidade, seu sorriso amargo e seu laconismo."

Condição e exigência para não mais odiar e invejar, que leva à idéia de uma deferência igualitária:

\footnotetext{
...ele não me faz nenhuma solicitação, nem eu the faço; nós somos iguais, talvez [o grande] não esteja tranqüilo, mas eu estou. Há uma filosofia que nos faz negligenciar os cargos e aqueles que nos proporcionam esses cargos; que nos isenta de desejar, de pedir, de rogar, de solicitar, de importunar. ${ }^{37}$
}

São os gestos, os movimentos, os olhares que fornecem, portanto, a matéria aos vínculos, às interações que conduzem ao sentimento de superioridade ou inferioridade. Deles nasceriam o respeito, a deferência ou o desprezo.

Os homens (...) reconhecem aqueles que lhes são iguais, sentem a superioridade que alguns têm sobre eles, e aquela que exercem sobre outros; daí nasce entre eles a familiaridade, o respeito ou a deferência, o orgulho ou o desprezo. Desta fonte advém que, em

36 LA BRUYÈRE, op. cit., p. 266.

37 Ibid., p. 266 e 366. 
lugares públicos ou onde as pessoas se reúnem, nos encontremos a todo momento entre aquele que procuramos abordar ou saudar e aquele que fingimos não conhecer e com o qual não queremos nos unir; que queiramos a honra de um e a vergonha de outro; podendo acontecer mesmo que aquele que vós honrais e quereis reter seja aquele que se sinta por vós incomodado e que vos deixe. ${ }^{38}$

Há algum meio de se furtar aos excessos da deferência? "Sobressairse por coisas que não dependam dos outros, mas unicamente de si mesmo", escreve La Bruyère. A questão, então, não seria tanto de se destacar mas de se aceitar, de ser aquilo que se é - respeitando seus limites. O valor social não se colocaria mais nos mesmos termos: ele seria atribuído, assegurado a todo homem, pobre ou poderoso, pelas instituições e sociedades democráticas. Eis os efeitos do fim dos privilégios e das hierarquias: cada um tem doravante "uma opinião elevada de seu valor pessoal".

"Renunciar a sobressair-se"? Le Bruyère enfrenta a questão com clareza: trata-se de um princípio inestimável, "pernicioso para os grandes, pois diminuiria sua corte, ou melhor, o número de seus escravos, destruiria sua empáfia juntamente com uma parte de sua autoridade, (...) lhes tiraria o prazer que experimentam com os rogos, as solicitações, ao fazer esperar ou recusar, ao prometer e nada dar." 39

As sociedades democráticas suprimiram as cortes; mas conseguiram banir "os conchavos, as intrigas, as disputas, a baixaria, a adulação" e reinstaurar "a dignidade às diferentes condições de homens, a serenidade em seus rostos"?

\section{O espirito das instituições democráticas: compartilhar a deferência}

As instituições democráticas que pretendem "dar genericamente aos homens uma alta idéia deles mesmos" conseguirão afastar os aduladores e obsequiosos, possibilitando, assim, que repensemos a ordem da deferência, essa ordem que implicava que alguns recebessem mais que outros? Os cortesãos,

38 LA BRUYÈRE, op. cit., p. 334

39 Ibid., p. 93-94. 
representantes dos tipos de caráter do século XVII, poderiam perdurar em outras sociedades?

A leitura de Tocqueville é aqui esclarecedora, quando evoca 1789 e as instituições democráticas que queriam "não somente destruir os privilégios, mas reconhecer e consagrar direitos". Teria a deferência algum lugar nesse projeto? Pode-se falar de deferência igualitária?

Um dos capítulos menos comentados de Da Democracia na América situa-se no centro dessa discussão. Nele, Tocqueville aborda a questão da austeridade dos americanos, para a qual vê duas causas: o orgulho e a alta idéia de si mesmos; a segunda, "mais íntima, mais poderosa", diz respeito ao fato de que nada parece estar fora de seu alcance. "Acredito que a austeridade dos americanos nasce, em parte, de seu orgulho", escreve, acrescentando que "nos países democráticos, o próprio pobre tem uma alta idéia de seu valor pessoal", o que afasta a vergonha originada de uma posição social inferior presente nas sociedades desigualitárias do Antigo Regime. ${ }^{40}$

Os americanos preocupam-se com a austeridade na apresentação que se fazem de si mesmos: é preciso ser grave para ser - ou parecer - digno. A austeridade não se acompanha facilmente da afetação e da contrição? Os americanos não tenderiam a experimentar em relação a si mesmos o que o cortesão outrora sentira em relação aos poderosos: o amor pela grandeza, por sua própria grandeza, deixando entrever a auto-suficiência que se exprimiria em uma atitude austera? A austeridade que emana de uma atitude contida, a impressão que provoca seria um dos meios de exprimir a deferência, e de obtêla.

As instituições democráticas parecem, dessa forma, encorajar certos traços de comportamento, de caráter, de temperamento e de humor tais como a gravidade, a seriedade, a austeridade como meios de traduzir e atribuir autoestima. Ora, essa auto-estima, essa deferência compartilhada depende de um mecanismo paradoxal na medida em que aparece ao mesmo tempo como efeito e causa, um elemento que permite o nivelamento das condições, mas também o auto-engrandecimento, a ausência de limites para cada um.

$\mathrm{O}$ orgulho que explica a austeridade dos americanos, observa Tocqueville, tem sua origem no método filosófico que consiste em "colocar

40 Ver TOCQUEVILLE, op. cit., cap. XV, "De la gravidité des Américainset pourquoi elle ne les empêche pas de faire souvent des choses inconsidérées", p. 187. 
apenas neles mesmos a regra de seu julgamento". ${ }^{41}$ Ela conduzirá à igualdade e terá conseqüências sobre a existência e a expressão da deferência nas sociedades democráticas.

Tocqueville assinala uma outra causa, que considera como "mais íntima e mais poderosa". É ela que "produz instintivamente nos americanos esta austeridade que [o] espanta". Doravante, todo bem é acessível ao habitante das democracias. Agitado, apressado, intempestivo, auto-suficiente, arrogante, "ele faz todas as coisas de forma apressada, contenta-se com mais ou menos e pára não mais que um momento para considerar cada um de seus atos." 42

Ocupar-se incessantemente, agir de forma inconsiderada; conceder pouco tempo e atenção às atividades, às interações, enfim, às pessoas.:

Assim, os povos democráticos são austeros, porque seu estado social e político os leva sem cessar a se ocupar (...), e agem inconsideradamente porque dão pouco tempo e atenção a cada uma destas coisas (...). O hábito da desatenção deve ser considerado como o maior vício do espírito democrático. ${ }^{43}$

Ora, a deferência - que pode depender da amabilidade, da urbanidade, do prazer das maneiras suaves e agradáveis, ou participar de um mecanismo sociológico - comporta uma parte intrínseca e irredutível de atenção (autêntica ou aparente), que pode ser de difícil aplicação nas democracias. Desatenção, pressa e orgulho próprio, auto-estima que se alimenta do olhar dos outros mas que se exprime na preocupação com a independência, na afirmação da autoconfiança e, em seguida, na arrogância e na auto-suficiência que valorizam de forma excessiva a apresentação de si. A sociedade democrática, que tolera e promove a desatenção, pode, então, encorajar - ou, ao menos, deixar que se instale - a indiferença, a inércia. Portanto, são esses os perigos que ameaçam as democracias.

No Antigo Regime, a atenção era concedida em função das condições e das hierarquias; e a maioria das pessoas, de fato, não recebia nenhuma atenção. $\mathrm{Na}$ democracia, a atenção deveria ser igualmente distribuída: cada indivíduo deveria recebê-la, mas, ao mesmo tempo, a pressa e o orgulho fazem com que essa necessidade não seja atendida e valorizada.

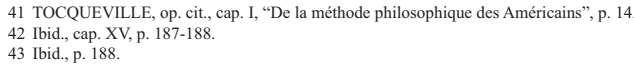


O fato da deferência sofrer desvios foi um aspecto sensível ao pensamento de La Bruyère; e igualmente ao de Tocqueville que se ateve a outras causas: a uma auto-confiança excessiva - provavelmente aparente -, encorajada por uma contínua incitação a modos de funcionamento e a valores exclusivos às sociedades democráticas. Assim, a desatenção torna-se apanágio de todos. A atenção sendo um componente da deferência, como fazer para respeitar o semelhante, o igual, sem lhe dar atenção?

Tocqueville busca compreender a ausência de deferência nos americanos e constata, em primeiro lugar, que eles "se moldam por outro costume". Em relação à deferência, o costume, nas sociedades do Antigo Regime, era imposto do exterior em função das hierarquias e das condições; o costume dos americanos consiste em "colocar apenas neles mesmos a regra de seu julgamento: o que leva seu espírito a outros hábitos”. Cada indivíduo, nessa ótica, apoia-se unicamente em si mesmo.

Tocqueville prossegue sua análise: "é ao seu próprio testemunho que eles têm costume de se referir", "eles apreciam", consequentemente, "ver com muita clareza o objeto do qual se ocupam; eles o retiram, portanto, tanto quanto possível, de seu envelope, afastam tudo que dele os separa e que o esconde dos olhares". ${ }^{44}$ Esta a razão pela qual os americanos não apreciam nem as formas nem as formalidades e vão diretamente ao essencial. "Esta disposição de espírito os conduz rapidamente a desprezar as formas" e, com elas, as formas de deferência que supõe o reconhecimento de uma ordem e a expressão das formas.

Devemos, portanto, concluir que é o sistema de deferência - seus modos de atribuição, de obtenção e de repartição - que, ao se modificar, altera o sentido quando, submetido à igualdade das condições, absorve os progressos do individualismo? Ou, ao contrário, devemos concluir que é a noção mesma de deferência que tende a desaparecer com a igualdade de condições?

Nesse sentido, Tocqueville ressalta uma conseqüência teórica, social e política presente na noção de revolução: toda revolução tem mais ou menos como efeito "remeter os homens a si mesmos e abrir no espírito de cada um deles um espaço vazio e sem limites". ${ }^{45}$ A liberdade e a igualdade fariam com que abandonassem as formas de dependência e de deferência tradicionais, o costume de se inclinarem face à opinião, seja dos antigos ou dos poderosos, incitando-os doravante a encontrá-las em cada um.

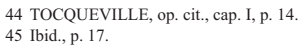


Mas o que isto significa? Trata-se apenas de se rejeitar a deferência institucional ou de uma recusa à toda deferência? É a possibilidade do respeito assegurado à cada homem que aqui se delineia, e em nenhum caso a garantia ou a certeza desse respeito.

Todas essas disposições psicológicas, todos esses sentimentos são contrários ao exercício da deferência, ao reconhecimento de sua ordem. Tocqueville conclui nos seguintes termos: "Cada um busca, então, se bastar empenhando-se em ter sobre todas as coisas crenças que lhe sejam próprias". 46

E não devemos nos espantar ao constatar que a democracia, tornando as relações habituais entre os americanos mais simples e fáceis, "não tenha associado mais fortemente os homens uns com os outros."

Quando a ordem das deferências estabeleceu-se em função do nascimento, o sistema subjacente era preciso e manifesto: cada qual conhecia o seu lugar na escala social, "ele não [procurava] ascender", "ele não [temia] ser rebaixado". Nas lutas que, opondo diferentes classes sociais, precedem a igualdade das condições, Tocqueville discerne "a inveja, o ódio e o desprezo pelo semelhante, o orgulho e a confiança exagerada em si mesmo". ${ }^{47}$

Suprimidos, os privilégios se reconstituem: as lutas para a obtenção da deferência, do valor e da utilidade social perduram sob outras formas.

Estabelece-se, então, uma guerra surda entre todos os cidadãos; uns, esforçando-se, através de mil artifícios, para penetrar, na realidade ou em aparência, entre aqueles que estão acima deles; outros, combatendo sem descanso para retirar desses usurpadores seus direitos, ou, o que é mais comum, o mesmo homem faz as duas coisas, enquanto procura introduzir-se na esfera superior, ele luta sem tréguas contra o esforço que vem de baixo. ${ }^{48}$

As conseqüências do fato de os americanos cultivarem excessivamente seu valor pessoal são a falta de atenção e a falta de consideração. "Um americano não se vê obrigado a demonstrar atenções particulares a cada um de seus semelhantes e nem cogita exigir isto para si mesmo."

46 TOCQUEVILLE, op. cit., p. 18.

47 Ibid., p. 149 e cap. I, p. 18.

48 Ibid., cap. II, "Comment la démocratie rend les rapports habituels des Américains plus simples et plus aisés", p. 149 
Respeitando cada homem em função de sua qualidade de ser humano, e não mais em função de uma condição ou hierarquia social, "não desprezando ninguém em razão de sua condição, ele não imagina que alguém possa desprezálo por esta mesma causa, e até que tenha percebido com clareza a injúria não acredita que queiram ultrajá-lo."49

É, então, legítimo pensarmos que esses americanos dos anos 1830 , não muito sensíveis às maneiras, às formas e aos detalhes, desprovidos de tato, opunham-se radicalmente aos membros da sociedade de corte, ignorando ou desprezando a sedução exercida pelas honras e precedências e, mais amplamente, pelos privilégios?

\footnotetext{
Observei várias vezes que, nos Estados Unidos, não é fácil fazer com que um homem compreenda que sua presença é importuna. (...) Eu contradigo um americano em todas as suas opiniões, para que ele sinta que seus discursos me fatigam; (...) mantenho um silêncio obstinado, e ele imagina que estou refletindo profundamente sobre as verdades que me apresenta; e, quando de súbito eu escapo finalmente a sua perseguição, ele supõe que um assunto urgente me chama lá fora. Este homem não compreenderá jamais que ele me exaspera sem que eu lhe diga, e eu não poderei dele escapar senão tornando-me seu inimigo mortal. ${ }^{50}$
}

Tocqueville propõe-se, então, a refletir sobre a psicologia, os sentimentos e os valores que acompanham o "exercício de uma deferência democrática". Indica que "o gênero humano experimenta necessidades permanentes e gerais", das quais a deferência faz parte. Dessas necessidades nasceram leis morais cuja "inobservância todos os homens naturalmente vincularam, em todos os lugares e em todos os tempos, à idéia de censura e de vergonha". ${ }^{51}$ É precisamente a inobservância, a ignorância e o distanciamento dessas leis morais que chocavam La Bruyère.

Tocqueville traça o percurso que vai do estado social e das instituições políticas da Idade Média às instituições democráticas; percurso que parte da dependência, da fidelidade, da deferência a um homem particular no interior da

49 TOCQUEVILLE, op. cit., cap. III, "Pourquoi les Américains ont si peu de susceptibilité dans leur pays et se montrent si susceptibles dans le nôtre”, p. 151.

50 Ibid.

51 Ibid., cap. XVIII, “De l'honneur aux États-Unis et dans les sociétés démocratiques”, p. 192. 
feudalidade. "Nas sociedades feudais, toda ordem pública apoiava-se portanto sobre o sentimento de fidelidade à pessoa do senhor."

\begin{abstract}
As sociedades democráticas, onde "cada um busca se bastar", vão modificar substancialmente as formas e a idéia mesma de deferência? Tocqueville, que vê uma relação estreita entre honra, glória, consideração e deferência, observa que os homens nas democracias seriam "mais descuidados com sua honra", acrescentando, no entanto: "idéia sutil e talvez falsa". ${ }^{52}$
\end{abstract}

É precisamente sobre esse tipo de questões que se debruçará Shils no final dos anos 1960. Constatando "uma atenuação da deferência explícita", "uma indiferença em relação a ela" nas sociedades democráticas contemporâneas, ele procurará saber se a deferência persiste nas relações entre iguais. Sublinha que se a minúcia do ritual tende a desaparecer, no entanto, a deferência não cessa de existir: "ela sobrevive sob uma forma difusa e impalpável que penetra todas as relações através do tom dos discursos, da postura, da precedência." ${ }^{53}$

Observa que é preciso adotar outra abordagem - até agora pouco desenvolvida - para estudar a deferência: uma abordagem que considere o fato de que a ela está "estreitamente ligada a fenômenos como os do prestígio, honra, respeito, renome, glória, dignidade", mas também, inversamente ligada "à obscuridade, vergonha, desonra, desrespeito, infâmia e indignidade". ${ }^{4}$

Defrontamo-nos aqui com um espaço difícil de ser apreendido. Espaço em que entrevemos as necessidades permanentes e gerais, colocadas por Tocqueville, um espaço em que se articulam os comportamentos e os sentimentos, e se exprimem, ou pelo menos se revelam, os sentimentos morais, individuais. Sentimentos pouco explicitados, mais experimentados que ditos às vezes difusos, e mesmo indefiníveis, eles não são facilmente qualificáveis, nem por aqueles que os observam ou pressentem nem por aqueles mesmos que os sentem. Sentimentos que podem ter inspirado acontecimentos políticos importantes e que inspiram, no presente, movimentos políticos decisivos como, por exemplo, os relativos às políticas de reconhecimento.

Podemos, assim, avançar para além da descrição empírica do uso dos títulos, das honras e dignidades, e também dos sentimentos inferidos por

52 TOCQUEVILLE, op. cit., p. 192

53 E. Shils, "Déférence", op. cit., p. 230-231.

54 Ibid. 
meio das posturas, para tentar precisar certas constantes ligadas às sociedades humanas, aos indivíduos? Podemos elucidar as razões pelas quais os homens gostam de se distinguir? Trata-se de uma necessidade de engrandecimento de si? Ou, de algo mais, aquilo que fundamentaria o sentimento mesmo de existir?

Gestos ou posturas podem provocar impressões, induzir sensações, refletir uma disposição psicológica, um certo estado de espírito. Compreendemos, então, o interesse em se estudar as expressões, as atitudes corporais, os gestos; aspecto ressaltado por Firth em sua pesquisa sobre as atitudes e os gestos de respeito.

A honra, a consideração, o reconhecimento, a auto-estima, o respeito, a deferência constituíram-se em objeto das reflexões morais nos séculos XVII e XVIII; hoje, a teoria moral e política faz da deferência um tema central, situado no cerne de reivindicações maiores em matéria de reconhecimento e respeito.

A releitura de um autor como La Bruyère ganha então todo o sentido, a moral e a ética intervindo para lembrar a importância do olhar social: o temor, a baixeza, a covardia que esse olhar estimula e reforça ou sobre os quais ele se cala. La Bruyère discerniu a ambigüidade e a duplicidade dos elos entre auto-estima e estima do outro, afirmando que "estimar-se significa igualar-se (...) quantas pessoas [entretanto] que vos sufocam de agrados, vos amam e estimam em particular, sentem-se incomodadas em público, e ao levantar-se ou na missa evitam vosso olhar e saudação?"55

Retomemos, ainda uma vez, as preocupações de Goffman quando reconhece que se o sentimento que acompanha a deferência é "banal", ele é "no entanto difícil de ser definido com precisão". Retomemos, igualmente, o pensamento de Firth que, questionando se "a antropologia social moderna não se afastou em demasia da realidade empírica", observa que nós temos nos mostrado mais interessados nos modelos do que nos comportamentos, nos símbolos do que nos usos e costumes. ${ }^{56}$ Não seria, portanto, conveniente voltarmos a conferir importância à observação e à qualificação dos comportamentos e dos sentimentos morais?

55 LA BRUYÈRE, op. cit., p. 224

56 Ver FIRTH, R. Symbols Private ans Public. Londres: George Allen and Unwin, 1973. p. 163. 


\section{Referências}

BARTHES, Roland. La Bruyère. Essais critiques. Paris: Ed. du Seuil, 1964.

ELIAS, N. La Société de cour. Paris: Calmann-Lévy, 1974.

FIRTH, R. Symbols Private ans Public. Londres: George Allen and Unwin, 1973.

GOFFMAN, Erving. Les Rites d'interaction. Paris: Minuit, 1974.

HAROCHE, Claudine. O direito à consideração: notas de antropologia política e história. Estudos de História, Franca, 2004.

HONNETH, A. The Struggle for Recognition. Cambridge, Massachusetts: MIT Press, 1996.

LA BRUYÈRE, J. de. Les Caractères ou les moeurs de ce siècle. Paris: Gallimard, 1951. Oeuvres Complètes. (Bibliothèque de la Pléiade).

LE GOFF, Jacques. Le rituel symbolique de la vassalité. In: LE GOFF, Jacques. Pour un autre Moyen Âge. Paris: Gallimard, 1991.

ROMAGNOLI, D. La courtoisie dans la ville: un modèle complexe. In: ROMAGNOLI, D. (Ed.). La Ville et la cour. Des bonnes et des mauvaises manières. Paris: Fayard, 1995.

SIMMEL, Georg. Custom, Law, Morality. In: WOLFF, Kurt H. (Ed.). The Sociology of Georg Simmel. New York: The Free Press, 1950.

SIMMEL, Georg. Sociologie et épistémologie. Paris: PUF, 1981.

SMITH, Adam. Théorie des sentiments moraux. Paris: PUF, 1999.

SPENCER, H. Ceremonial Institutions. London: Williams and Norgate, 1879. Part IV, "Principles of Sociology".

THOMAS, K. Introduction. In: BREMMER, J.; ROODENBURG, H. (Eds.). A Cultural History of Gesture (from Antiquity to Present Day). New York: Polity Press, 1991.

TOCQUEVILlE, Alexis de. De la démocratie en Amérique. 1. ed. histórico-crítica revista e ampliada por Eduardo Nolla. Paris: Vrin, 1990.

TÖNNIES, F. Die Sittre. Glencoe: The Free Press of Glencoe, 1961. Trad. Ingl. On Custom.

WALZER, M. Spheres of Justice. New York: Basic Books, 1983.

WEBER, M. Économie et Société. Paris: Plon, 1971. 